\title{
ADUBAÇÃO NPK E CALAGEM NA PRODUÇÃO DE MASSA VERDE E SEMENTES DE CROTALÁRIA ${ }^{(1)}$
}

ANTONIO LUIZ DE BARROS SALGADO (2), ANiSio AZZINI, Seção de Plantas Fibrosas, CELI TEIXEIRA FEITOSA (2), Segão de Fertilidade do Solo, ARMANDO PETINELLI, Estaçāo Experimental de Tatui, e ARY ARRUDA VEIGA, Estação Experimental de Tietê.

\section{RESUMO}

São relatados dois experimentos de campo visando avaliar o efeito de nitrogênio, fósforo e potássio na presença e na ausência de calcário, na produção de massa verde e de sementes de crotalária. Os experimentos foram realizados no Centro Experimental de Campinas e na Estação Experimental de Tatui, em Latossolo Roxo, no ano agrícola de $1969 / 70$. Os resultados obtidos mostram claramente que o efeito para a utilização do fósforo foi significativo em solos com menor teor deste elemento e que houve efeito altamente positivo para o emprego do calcário na localidade de Tatuí.

\section{INTRODUÇÃO}

A cultura da crotalária (Crotalaria juncea L.) para fins de exploração de fibras destinadas à indústria de papéis finos já ocupa a atenção de inúmeros agricultores no Estado de São Paulo. Praticamente toda a área paulista, exceto a região Sul e Ribeira, apresenta condições bastante satisfatórias de clima e solo para esse cultivo, cujas informações sobre adubação e calagem são muito escassas, praticamente inexistentes na literatura.

(1) Recebido para publicação a 23 de junho de 1980.

(2) Com bolsa de suplementação do CNDCT-CNPq. 
SALGADO et alii $(\mathbf{2 , 3})$ estudaram o efeito de adubação NPK e adubação fosfatada na cultura da crotalária, concluindo que a adubação fosfatada é indicada e eleva acentuadamente a produção de massa verde, assim como a adubação completa é eficiente em solos extremamente pobres.

Diversos autores, trabalhando com leguminosas, indicam ser o $\mathrm{pH}$ mais próximo da neutralidade, em torno de 6,00-6,50, o que melhores condições apresenta para o desenvolvimento destas culturas.

O trabalho foi desenvolvido visando estudar o efeito da adubação nitrogenada, fosfatada e potássica na ausência e na presença de calcário na cultura da crotalária para a produção de massa verde e sementes.

\section{MATERIAL E METODOS}

Os experimentos foram realizados no ano agricola de 1969/70, nas Estações Experimentais de Tatuí e Campinas, pertencentes ao Instituto Agronômico do Estado de São Paulo, em solos classificados como Latcssolo Roxo (BRASIL, 1).

Amostras de terra retiradas da camada superficial $(0-20 \mathrm{~cm})$ apresentaram as seguintes características químicas:

\begin{tabular}{|c|c|c|c|c|c|c|}
\hline \multirow{2}{*}{ Local } & \multirow{2}{*}{$\mathrm{pH}$} & \multirow{2}{*}{$\begin{array}{c}\text { Carbono } \\
\%\end{array}$} & $\mathrm{PO}_{4}^{3-}$ & $\mathrm{K}+$ & $\mathrm{Ca}^{2+}+\mathrm{Mg}^{2+}$ & $\mathrm{Al}^{3+}$ \\
\hline & & & \multicolumn{4}{|c|}{ e.mg/100 $\mathrm{ml}$ de T.F.S.A. } \\
\hline Campinas ... & 5,2 & 1,00 & 0,34 & 0,16 & 1,20 & 2,00 \\
\hline Tatuí & 5,3 & 1,70 & 0,14 & 0,37 & 2,40 & 1,50 \\
\hline
\end{tabular}

Os experimentos foram instalados na melhor época de plantio, novembro, para uma germinação perfeita e uniforme, enıregando-se a variedade Comum, que, de longa data, vem sendo cultivada como adubo verde e produtora de fibras.

O delineamento experimental utilizado foi o fatorial $3^{3}$ para NPK, distribuído em três blocos, em presença e na ausência de calcário. O calcário dolomítico foi aplicado na dose de $2 \mathrm{t} / \mathrm{ha}$, tendo sido espalhado uniformemente e incorporado ao solo 60 dias antes do plantio. Os canteiros que receberam calagem foram sorteados em cada bloco.

Os niveis dos elementos fertilizantes empregados, em quilogramas por hectare, foram 0,30 e 60 de $\mathrm{N} ; 0,60$ e 120 de $\mathrm{P}_{2} \mathrm{O}_{5}$, e 0,30 e 60 de $\mathrm{K}_{2} \mathrm{O}$, respectivamente na forma de salitre-do-chile, superfosfato simples e cloreto de potássio. Os fertilizantes foram misturados previamente, espalhados uniformemente sobre os respectivos canteiros e incorporados ao solo com rastelo antes do plantio. 
Os canteiros apresentavam dez linhas com $5 \mathrm{~m}$ de comprimento, espaçados de $0,20 \mathrm{~cm}$, sendo consideradas oito linhas úteis e duas bordaduras; a densidade de semeação foi $90 \mathrm{~kg} / \mathrm{ha}$, distribuídas uniformemente no interior dos sulcos.

A colheita se deu aproximadamente 150 dias após a germinação, quando se computaram massa verde e peso de sementes.

\section{RESULTADOS E DISCUSSÃO}

Os dados de produção em quilograma/hectare de massa verde e de sementes de crotalária para as localidades de Campinas e Tatuí dos ensaios de adubação NPK e calagem são apresentados nos quadros 1 a 4 .

Os tratamentos com calcário na localidade de Campmas não apresentaram diferenças significativas quando se estudou a produção de massa verde. o mesmo sendo observado para o tratamento sem calcário. Para a produção de sementes, quando se utilizou o calcário, não houve efeito significativo para nenhum dos tratamentos, porém nos tratamentos sem calcário houve significância para fósforo e a interação fósforo e potássio.

Não foi observado efeito de calagem tanto para a produção de massa verde como de sementes. Os coeficientes de variação foram da ordem de 35,$70 ; 41,70 ; 33,90$ e $28,60 \%$ respectivamente para produção de massa verde e produção de sementes, com e sem calcário.

SALGADO et alii (3) mostraram um aumento de produtividade altamente significativo ao utilizar o fósforo, tanto para a produção de massa verde como de sementes, na regiāo de Campinas, em que o teor de $\mathrm{PO}_{4}{ }^{3-}$ no solo era 0,03 e 0,07 e.mg $/ 100 \mathrm{ml}$ de T.F.S.A. $\mathrm{Na}$ localidade de Tatui, verificaram efeito linear do fósforo quando estudaram a produção de massa verde, para os tratamentos com e sem calcário, porém, para a produção de sementes, observaram efeito significativo para o fósforo, linear no tratamento sem calcário.

SALGADO et alii (3), em estudos realizados na Estação Experimenta] de Tatuí, sem o emprego de calagem, observaram que o emprego de fósforo aumentou significativamente a produção de massa verde e sementes; o nitrogênio apresentou efeito significativo em um dos experimentos e não-significativo no outro, ao passo que o efeito do potássio foi praticamente nulo, só apresentando significância quando $€ m$ presença do fósforo ou do fósforo e nitrogênio juntos. Por outro lado, houve efeito altamente significativo para calagem quando estudaram a produção de massa verde e de sementes.

Os coeficientes de variação foram respectivamente 36,$00 ; 34,90$; 46,40 e $41,80 \%$ para produção de massa verde e de sementes com e sem calcário. 


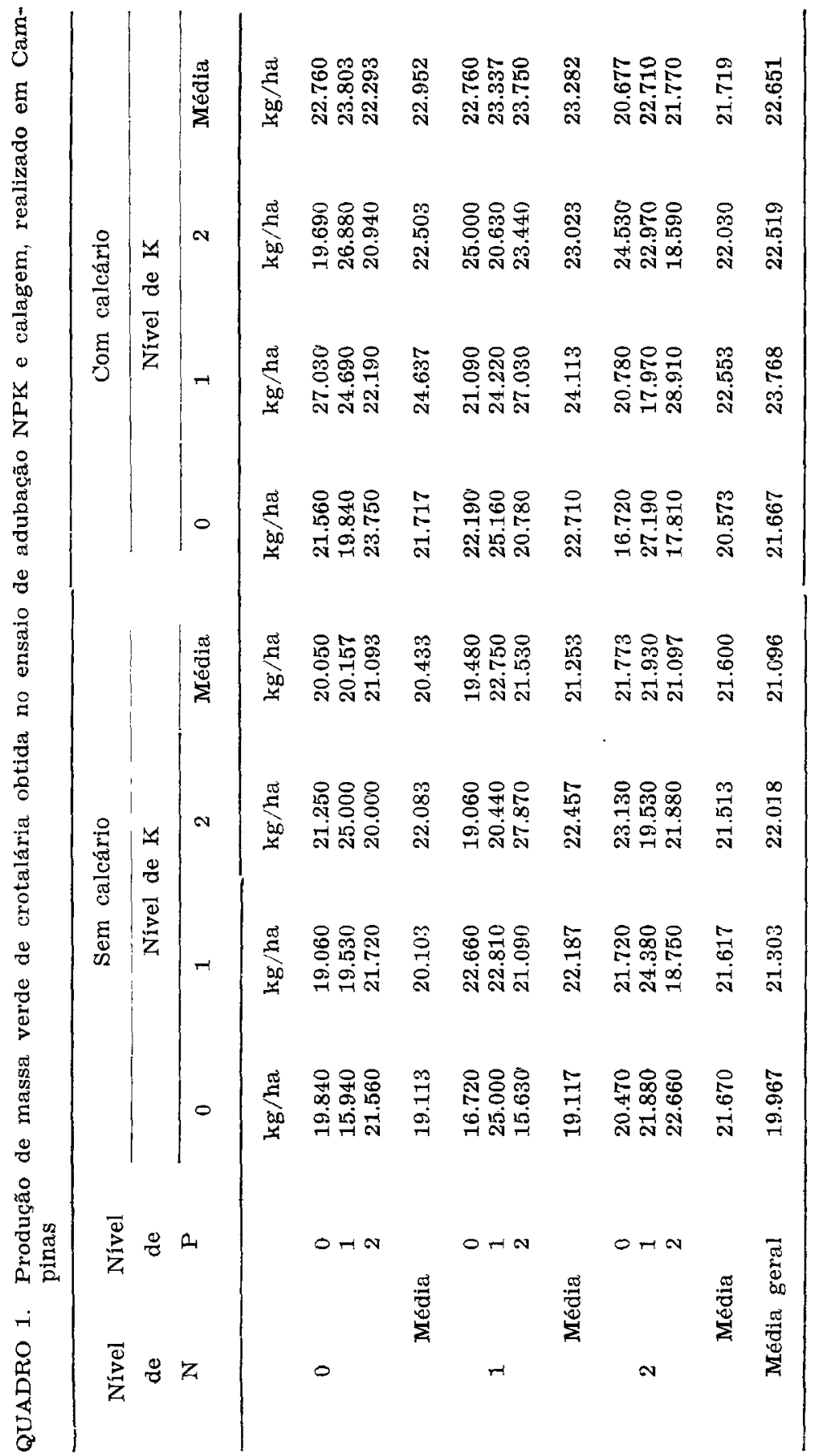




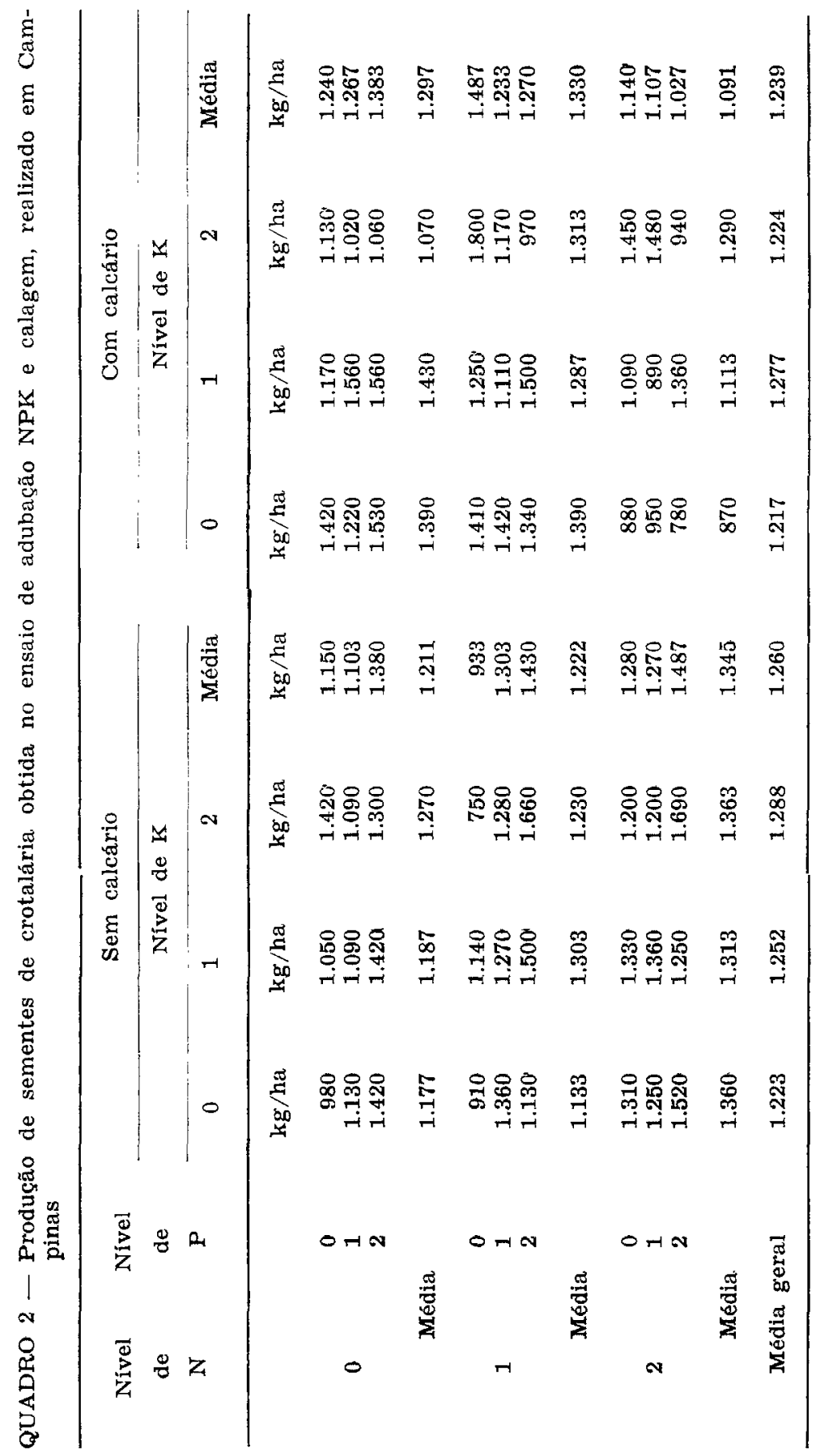




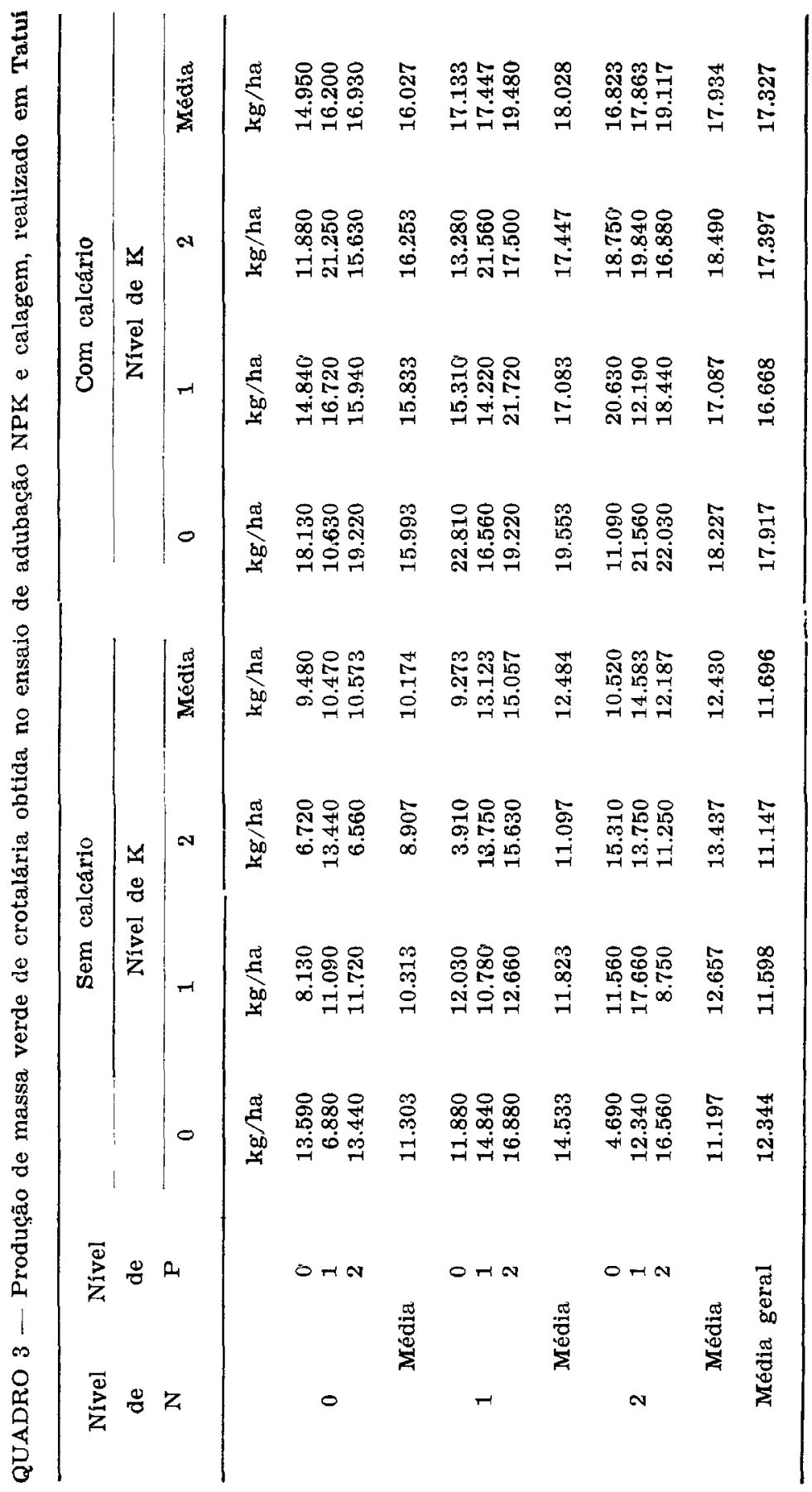




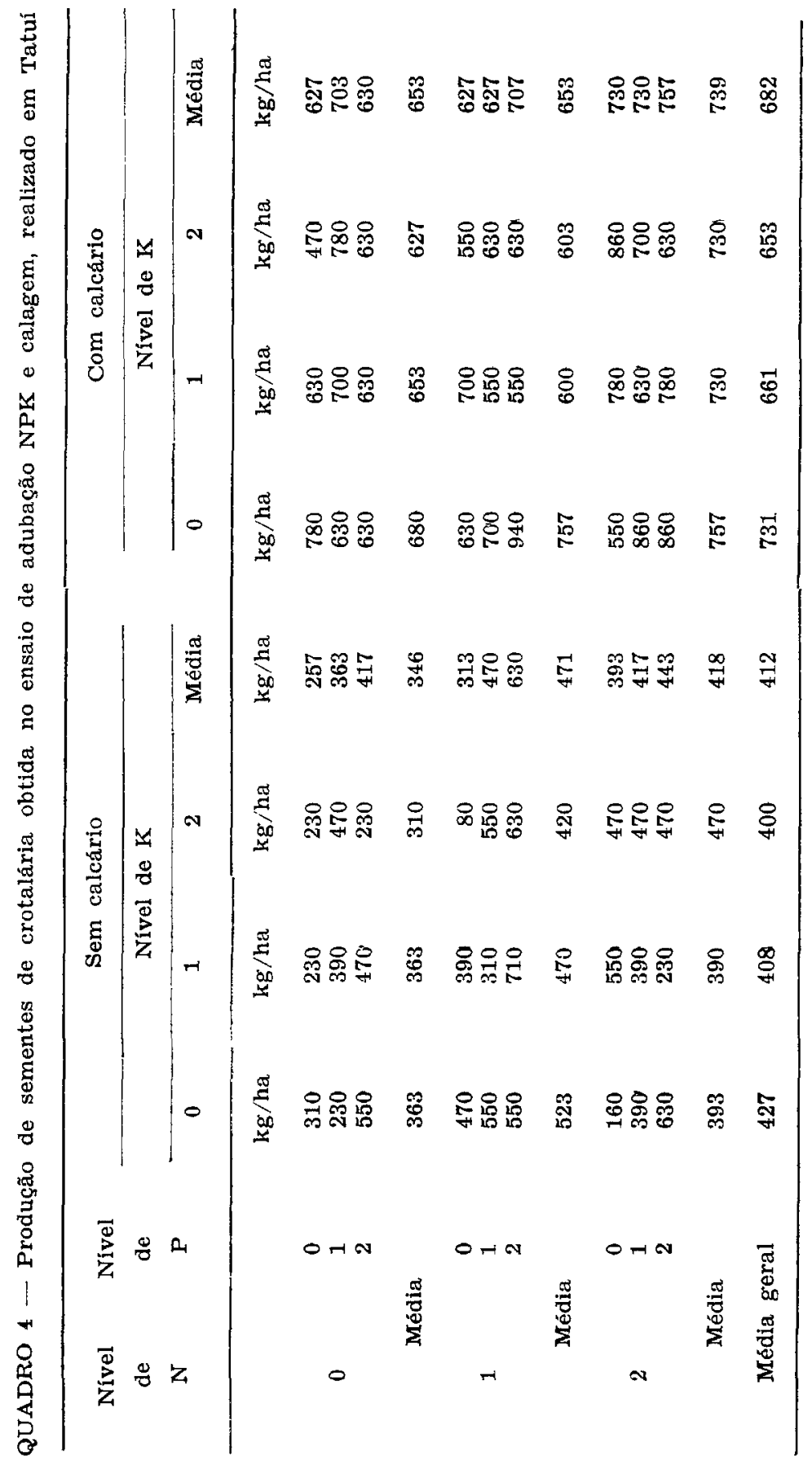


Apesar de os experimentos apresentarem elevados coeficientes de variação, ainda assim se observam efeitos para fósforo, principalmente para os experimentos conduzidos em Tatuí em solo com teor mais baixo deste elemento, na ausência e na presença de calagem.

\section{CONCLUSõES}

A análise dos resultados permite tirar as seguintes conclusões:

a) $O$ emprego da calagem se mostrou altamente benéfico para a cultura, apresentando aumento na produtividade de massa verde e sementes, principalmente para o experimento conduzido na Estação Experimental de Tatuí.

b) O aumento ocasionado pelo fósforo foi maior em solos cujo teor deste elemento era mais baixo.

\section{SUMMARY}

\section{EFFECT OF NPK FERTILIZATION AND LIMING ON THE GREEN MATTER AND SEED PRODUCTION OF SUNN HEMP (CROTALARIA JUNCEA L.)}

Two field experiments were conducted in order to evaluate the effect of $N$, $P, K$ fertilization, with and without liming, on the total green matter and seed production of sunn hemp (Crotalaria juncea L.). The experiments were done in the experimental stations of the Instituto Agronomico of State of São Paulo, Brazil, located in Campinas and Tatui, during the years of $1969 / 1970$, in soils of the group Latosol «Roxo». The results obtained indicated a positive effect of $P$ fertilization on the sunn hemp yield, in the soils that presented less soil $P$ content. Significant increases in yield were obtained with the application of dolomitic lime, specially in the experimental station of Tatui.

\section{REFERENCIAS BIBLIOGRÃFICAS}

1. BRASIL. Ministério da Agricultura. Levantamento de reconhecimento dos solos do Estado de São Paulo: contribuição à Carta de Solos do Brasil. Rio de Janeiro, Centro Nacional de Ensino e Pesquisas Agronômicas, 1960. 634p. (Boletim do Serviço Nacional de Pesquisas Agronômicas, 12.)

2. SALGADO, A.L.B. Competição de fertilizantes fosfatados na cultura da crotalária (Crotalaria juncea L.). Piracicaba, Escola Superior de Agricultura Luiz de Queiroz», 1978. 61p. Tese de Mestrado.

3. —__ AZZINI, A.; FEITOSA, C.T.; PETINELLI, A.; SORDI, G. de. Efeitos da ađubação NPK na cultura da crotalária (Crotalaria juncea L.). Bragantia, Campinas, 41:21-33, 1982. 